\title{
Social sciences for food and health research
}

\author{
Mark McCarthy
}

Received: 5 October 2012/Accepted: 14 February 2013/Published online: 9 March 2013

(c) Springer-Verlag Berlin Heidelberg 2013

\begin{abstract}
Healthier eating is a global challenge for chronic disease control. Food and Health Research in Europe (FAHRE) surveyed research structures and programmes in 32 countries, and reviewed research needs and gaps across nine themes. Food processing and safety research, nutrition and molecular research, and diseasebased clinical research are strong; but research is weak on determinants of disease and healthier eating through policies and changing behaviours. Biomedical and commercial research for patents contrast with social research for the public interest. More funding and capacity support should go to social research in the food and health sector.
\end{abstract}

Keywords Research priorities · Nutrition policy ·

Social sciences

One of the most striking epidemiological trends of the twentieth century in food and health is related to food (Fig. 1). Cancers of the lung and stomach both have poor survival, and mortality rates in these slowly developing cancers show after long environmental exposure. The cigarette epidemic, starting first in men in the first half of the twentieth century, and in the second half in women, has brought its toll of lung cancer (and heart disease) (Levi et al. 2003). But, following a rise in the nineteenth century (Sonnenberg 2011), stomach cancer rates have fallen consistently through the second half of the century (Levi et al. 2003), and from third to fourteenth place in the

\section{McCarthy $(\square)$}

Department of Epidemiology and Public Health,

University College London, 1-19 Torrington Place,

London WC1E 6BT, UK

e-mail: m.mccarthy@ucl.ac.uk frequency of cancers. This public health benefit happened without active policy, or effective medical interventionsand we do not really know why. The parallel rates of improvement for both men and women indicate shared environmental factors (rather than the gendered behaviours in smoking), including the rise in refrigeration, imported fresh fruit and vegetables around the year, reduced use of meat preservatives (stomach cancer rates are high in Japanese with high-salt diets) and changing infection with $H$. pylori (Crew and Neugut 2006).

In 2011, the United Nations held its second only summit to address the global challenge of chronic diseases (World Health Organisation 2011). The first summit, a decade ago, was for HIV/AIDS. As infectious diseases are being controlled through improved sanitation, hygiene and vector control, chronic diseases-including cancer, stroke, heart disease, stroke and diabetes-now cause up to $80 \%$ of deaths globally. And four risk behaviours-smoking, alcohol, lack of exercise and unhealthy eating-are dominant risk factors for premature mortality. Since we know the risk factors, what should be done?

Through a call from the European Commission's Seventh Framework Research Programme, we have studied the food and health research programmes in EU member states. FAHRE (Food and Health Research in Europe) described the food and health research systems for 32 European countries (FAHRE 2012) - both public and industry-and assessed the needs and gaps for research (FAHRE 2011; McCarthy et al. 2011). There have previously been separate analyses of agriculture and food (EU Agri Mapping 2008) and public health (McCarthy and Clarke 2007; Conceicao et al. 2009) research systems, as well as road maps for biomedical research on chronic diseases (DIAMAP 2010; European Respiratory Society 2012). In FAHRE, we found much food research focused towards 


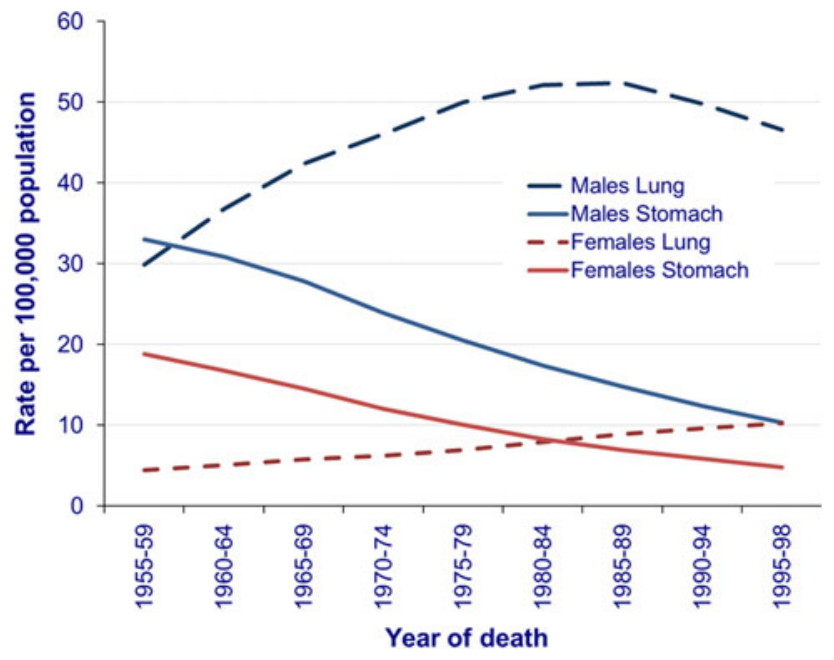

Fig. 1 Age-standardised mortality rates for lung and stomach cancers, by sex, European Union (15 member states in 1995-1998), 1955-1998 (Cancer Research UK 2012)

technologies for food processing and food safety, micronutrients, molecules and genomics, and biomedical research on specific diseases. But there was little research on theories, methods and impacts of food policy, health promotion and nutrition practice (McCarthy et al. 2011).

The European Commission is currently placing great emphasis on innovation to link research to economic benefits and encouraging legal patents so that knowledge can be protected for commercial development (European Commission 2012). Research funding is being directed towards fields with tradeable products and services, such as information technology. While food production is also a big component of national economies, healthy eating is a notfor-profit, non-tradeable behaviour. Food and health research has to be supported by public funds, and its impact must be measured by its benefit to society (McCarthy 2012).

Our genes are static, but epidemiological trends demonstrate the major risks and benefits to health of environmental and social change. We know we are eating the wrong food, and increasingly too much of it. Our governments seek to reverse these trends, at the level of the United Nations and through national policies. Research evidence is needed on the effectiveness of nutritional guidelines (WHO 2012), of the impact the food industry (C3 Collaborating for Health 2012) - the patterns of food production, processing, marketing and sales-and of the regulatory and cultural environments that determine consumption (IASO 2012). We need evidence for policy and interventions. And because we are linked politically, these are opportunities for collaborative research across Europe (McCarthy et al. 2013).

For several decades, the popular image of science has been the laboratory, with white coats, flasks and pipettes.
In the twenty-first century, the biomedical and life sciences research budget has focused towards systems biology. Genome-wide association studies have significant challenges in determining the causal pathways of the major chronic diseases, and the hope of 'personalised' medicine for these diseases remains elusive (Janssens and van Duijn 2008). The population sciences that have demonstrated the links between social behaviours and disease patterns; and social sciences are needed to achieve effective interventions for healthier populations. Similarly, infrastructure grants are needed for fieldwork rather than equipment and support for young researchers in the social sciences as much as biomedicine. Maintaining the current biomedical and commercial paradigm of food and health research could prevent the aspirations of the United Nations. Directing national research agendas towards the sociomedical and public sector sciences could benefit the lives of millions of European citizens.

Acknowledgments This work was undertaken as dissemination of the European Union Seventh Framework Project FAHRE (Food and Health Research in Europe), contract number 245278.

\section{References}

C3 Collaborating for Health (2012) Food and health research: a key role for the private sector. http://www2.spi.pt/fahre/reports/ C3report\%20for\%20FAHRE.pdf. Accessed 2 Oct 2012

Cancer Research UK (2012) Stomach cancer mortality statistics. www.cancerresearchuk.org/cancer-info/cancerstats/types/stomach/ mortality/uk-stomach-cancer-mortality-statistics. Accessed 2 Oct 2012

Conceicao C, Leandro A, McCarthy M (2009) National support to public health research: a survey of European ministries. BMC Public Health 9:203

Crew KD, Neugut AI (2006) Epidemiology of gastric cancer. World J Gastroenterol 12(3):354-362

DIAMAP (2010) Strategic plan for diabetes research. http://www. DIAMAP.eu. Accessed 3 Mar 2013

EU Agri Mapping (2008) The European agricultural and food research: mapping current capacity, assessing future perspectives. http://ec.europa.eu/research/biosociety/inco/projects/0071_ en.html. Accessed 2 Oct 2012)

European Commission (2012) 2011 Impact assessment accompanying the communication from the commission 'Horizon 2020-the framework programme for research and innovation'. European Commission, Brussels, (SEC(2011), p 1427)

European Respiratory Association (2012) European respiratory roadmap, chapter 3: research. http://www.ersroadmap.org/healthcareprofessionals/research-chapter-3.html. Accessed 2 Oct 2012

FAHRE (Food and Health Research in Europe) (2011) Food and health research needs in Europe: synthesis of thematic expert reports. http://www2.spi.pt/fahre/reports/research_needs_ synthesis.pdf. Accessed 2 Oct 2012

FAHRE (Food and Health Research in Europe) (2012) Mapping food and health research programmes in Europe: synthesis of the 32 country. http://www2.spi.pt/fahre/reports/FAHRE_Mapping Synthesis.pdf. Accessed 2 Oct 2012 
IASO (International Association for the Study of Obesity) 2012 A junk-free childhood 2012: marketing foods and beverages to children in Europe. http://www.iaso.org/policy/euprojects/ stanmarkproject. Accessed 2 Oct 2012

Janssens ACJJ, van Duijn CM (2008) Genome-based prediction of common diseases: advances and prospects. Hum Mol Genet 17. Rev Issue 2:R166-R173. doi:10.1093/hmg/ddn250

Levi F, Lucchini F, Negri E, Boyle P, La Vecchia C (2003) Mortality from major cancer sites in the European Union, 1955-1998. Ann Oncol 14(3):490-495

McCarthy M (2012) Transforming research for food and health in Europe. Eur. J Clin Nutr. Advanced publication. doi: 10.1038/ejcn.2012.90

McCarthy M, Clarke A (2007) European public health research literatures-measuring progress. Eur J Public Health 217(Suppl 1): $2-5$

McCarthy M, Aitsi-Selmi A, Bánáti D, Frewer L, Hirani V, Lobstein T, McKenna B, Mulla Z, Rabozzi G, Sfetcu R, Newton R (2011)
Research for food and health in Europe: themes, needs and proposals. Health Res Policy Syst 9:37

McCarthy M, Cluzel E, Dressel K, Newton R (2013) Food and health research in Europe: structures, gaps and futures. Food Policy 39:64-71

Sonnenberg A (2011) Time trends of mortality from gastric cancer in Europe. Digest Dis Sci 56(4):1112-1118

World Health Organisation European Regional Office (2012) WHO European action plan for food and nutrition policy 2007-2012. www.euro.who.int/en/what-we-do/health-topics/disease-prevention/ nutrition. Accessed 2 Oct 2012

World Health Organisation (2011) United Nations high-level meeting on noncommunicable disease prevention and control, 19-21 September 2011. http://www.who.int/nmh/events/un_ncd_ summit2011/en. Accessed 2 Oct 2012 